\author{
O. Shpak, I. Studenyak, I. Shpak
}

\title{
Temperature Dependence of the Refractive Index of Vitreous Alloys of the Ag-As-S System
}

\author{
Uzhgorod National University, Ukraine, Uzhgorod, Pidhirna Street, 46; e-mail: shpak.univ@gmail.com
}

\begin{abstract}
The temperature coefficient of refractive index $d n / d T$ is determined for glassy alloys of the system along the $\left(\mathrm{Ag}_{2} \mathrm{~S}\right)_{\mathrm{x}}\left(\mathrm{As}_{2} \mathrm{~S}_{3}\right)_{100-\mathrm{x}}$, direction $(0<\mathrm{x}<20)$ in the spectral interval of $1-5 \mu \mathrm{m}$ at temperature of $77-400 \mathrm{~K}$. The glasses in question are shown to take negative values of $d n / d T$ depending on the composition and wavelength. The dependence of the coefficient on spectrum and temperature is studied using a single oscillator model.

Keywords: chalcogenide glasses, temperature coefficient of refractive index, single oscillator model, absorption band.
\end{abstract}

Article acted received 03.05.2018; accepted for publication 15.09.2018.

\section{Introduction}

Chalcogenide glassy semiconductors (CHF) with significant content of silver are used as ion-selective membranes, solid-state current sources and other electrochemical devices [1-4]. An increase in the amount of silver in the synthesis of glassy semiconductors in the Ag-As-S system leads to a significant change in their physical and chemical properties, which exacerbates the interest in the study of the concentration dependence of the parameters of the glasses of this system. So the density, microhardness, electrophysical and dielectric parameters of the glasses change most strongly at an Ag content up to $\sim 5$ at. $\%$, And at a concentration of silver more than 8-10 atom\% of Ag-As-S alloys are one of the few chalcogenide glasses with high ionic conductivity [45]. Accordingly, the main attention was drawn to the study of the electrical and dielectric parameters of these materials, at the same time, the optical properties are insufficiently studied.

In connection with the creation of sources of powerful short light pulses - lasers, the problem of studying the temperature behavior of the refractive index has become relevant [6]. The study of the thermo-optical effect (change in the refractive ability of a substance with temperature change) is important for predicting changes in the characteristics of the corresponding optical materials under different temperature conditions. In the passage of laser radiation through the condensed media there is an additional refraction associated with the heating of matter by absorbing the energy of radiation, that is, this phenomenon can be used as a tool for research.

The use of CHF in optoelectronics as active and passive elements makes it necessary to study their thermo-optical properties. An important, from a practical point of view, information can be obtained by examining the dispersion and temperature dependence of the refractive index, which allows us to determine the composition of glasses with positive, negative and zero temperature changes in a wide temperature range. The possibility of obtaining such compositions makes it possible to coordinate the elements of various types of optical systems, the criterion of which is the equality of thermoelectric aberrations of elements.

The temperature coefficient of refractive index $(\mathrm{T})$ is the main value, which is included in the expression for various thermo-optical constants, which are used for calculating thermo-optical and thermo-wave aberrations of optical systems [6]. In directories and documents on optical glasses the value of two thermooptic constants $W_{T}$ and $V_{T}$ is given. The glass constant $W_{T}=\frac{d n}{d T}+\alpha_{L}(n-1)$ characterizes the change in the optical beam length in a glass with a temperature change of one degree, provided that there is no thermoelastic stresses in the glass and is used in calculations of the thermo-wave aberrations of the optical system, which operates in an uneven temperature field. When calculating thermo-optical aberrations, the position and magnification of optical systems operating at a temperature different from that of a room use a thermo- 
optical constant $V_{T}=\frac{1}{n-1} \frac{d n}{d T}-\alpha_{L}$, where $n$ is the refractive index, and $\alpha_{L}$ is the linear expansion coefficient.

The criterion of the glass's thermality is the value of the sum $\left(W_{T}+R\right)$, which determines the value of the thermo wavelength distortion of the optical parameters in the event of the radial temperature difference $[7,8]$ :

$W+R=[\beta+\alpha(n-1)]+\left[\alpha(n-1)\left(\mu-\frac{\alpha E\left(C_{1}+C_{2}\right)}{2}\right)\right]$

where $R$ is an independent component of the TPP, which determines the change in the electron polarization with temperature [7], $\beta=d n / d T$ is the temperature coefficient of the refractive index, $\mu$ is the Poisson constant, $E$ is the Young modulus, $C_{1}$ and $C_{2}$ are photomultiplic constants. In [8] it is shown that the value of the sum of thermopotic constants is determined mainly by the value of $W_{T}$, which is considered to be a practical criterion for the atermality of glasses of various purposes [6].

In this paper, experimental results of the study of the concentration and temperature behavior of the refractive index of glass-fiber alloys of the Ag-As-S system on the incision $\left(\mathrm{Ag}_{2} \mathrm{~S}\right)_{\mathrm{x}} \cdot\left(\mathrm{As}_{2} \mathrm{~S}_{3}\right)_{100-\mathrm{x}}, \mathrm{x}=0-20$ mol \%.

\section{Method of experiment}

The Ag-As-S glasses in the $\mathrm{Ag}_{2} \mathrm{~S}-\mathrm{As}_{2} \mathrm{~S}_{3}$ section were prepared by direct synthesis of especially pure elemental components in evacuated $\left(\sim 1.5 \times 10^{-3} \mathrm{~Pa}\right)$ quartz ampoules. The weight of the weights was 5-10 g. The ampoules with the initial components were heated in a silo furnace to $600{ }^{\circ} \mathrm{C}$ at a rate of $30-40$ degrees per hour and held at that temperature for 8 hours. Further, the temperature was raised to $950{ }^{0} \mathrm{C}$, kept at such a temperature of 2-2,5 hours, and then was cooled to 600 ${ }^{0} \mathrm{C}$ at a rate of $100 \mathrm{deg} / \mathrm{h}$, followed by quenching samples in the air. Optical glasses with a maximum content of 20 mole\% $\mathrm{Ag}_{2} \mathrm{~S}$ were obtained for the $\mathrm{Ag}_{2} \mathrm{~S}$ $\mathrm{As}_{2} \mathrm{~S}_{3}$ section. According to the results of X-ray and microstructural studies, the models had a homogeneous structure. The absence of crystalline inclusions was confirmed by the microsilicon viewing in a microscope MIC-1. The density of the glass was determined by the method of hydrostatic weighing in toluene with an error of $0.5 \%$.

Measurement of the dispersion and temperature behavior of the refractive index $n$ was carried out by the prism method in the spectral range of $0.6-12 \mu \mathrm{m}$ on the installation and in the manner described in [9]. In the spectral range $0.6 \div 0.84 \mu \mathrm{m}$, a monochromator MDR-3 was used, in the near and middle IR region - an ICS-21 spectrophotometer. Prism models were mechanically polished to class 14 with cleanliness, the area of their working surfaces was $5 \times 10 \mathrm{~mm} 2$ and the angles between them $\sim 10-12^{0}$. Measurement of refractive angles of prism was carried out on the goniometer GS1.5 of the LOMO company. The angles of deflection of the light beam in the prisms were fixed using a prefix, assembled on the basis of the optical dividing head EDG10 , which allows to count the angular values up to 10 '.
The refractive index was calculated according to the formula

$$
n=\frac{\sin (\varphi+\delta)}{\sin \varphi}
$$

where $\varphi$ is the angle of the prism, $\delta$ is the angle of the beam deviation when passing through the prism. The measurement accuracy $n$ in the entire investigated spectral region was $1 \times 10^{-3}$. Dilatometric measurements were made on a vertical quartz dilatometer with a capacitive gauge of elongation and a measurable effort of no more than $0.3 \mathrm{~N}$ in the temperature range from room to deformation of alloys. The programmable temperature controller provides linear heating with different speeds. The temperature was recorded with a chromel-alumel thermocouple. The measuring cell allowed to calculate elongation with an accuracy of $10^{-4}$ and determine the coefficient of linear expansion with an error of $\pm 5 \%$.

\section{Experimental results and discussion}

According to [10-13], the temperature dependence of the refractive index can be described by the following formula:

$$
\frac{d n}{d T}=\left(\frac{\partial n}{\partial T}\right) \rho-\beta \rho\left(\frac{\partial n}{\partial \rho}\right),
$$

where $\rho$ is the density, $\beta$ is the volume expansion coefficient. The first term in the right-hand side of equation (3) characterizes the change $n$ due to the refraction change, the second one due to the photoluminescence effect. Unlike oxide glasses, for which the first term in (4) is always much larger than the second [11], in the case of chalcogenide glass, these members are of the same order, which allows the glass with positive, zero and negative values of $d n / d T$ to be obtained.

Pokkel has found that the temperature changes of the refractive index of solids are due to two factors [14]: the deformation that occurs when the temperature changes, which, due to the photovoltage effect, causes a change in the refractive index; direct influence of temperature on refractive index. Consequently, the temperature behavior can be described by the formula:

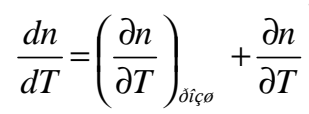

In this formula $d n / d T$ is an experimentally observed change in the refractive index due to temperature variation, $(\partial n / \partial T)_{\text {expansion }}$ is a change caused by thermal expansion, and $\partial n / \partial T$ is the true temperature coefficient of refractive index variation.

In general, when investigating the thermo-optical properties of glasses, attempts are made to detect and separately evaluate the effects of the change in the number of particles per unit volume, the dependence of polarization on density (photovoltaic effect) and the dependence of polarizability on temperature, assuming that these effects form three independent components of the quantities $d n / d T$. To analyze the dependences of $n(T)$, mainly dispersion expressions similar to those of Zellmeyer or Lorentz Lorentz $[10,15]$ are used, where the coefficient $d n / d T$ is based on the temperature 


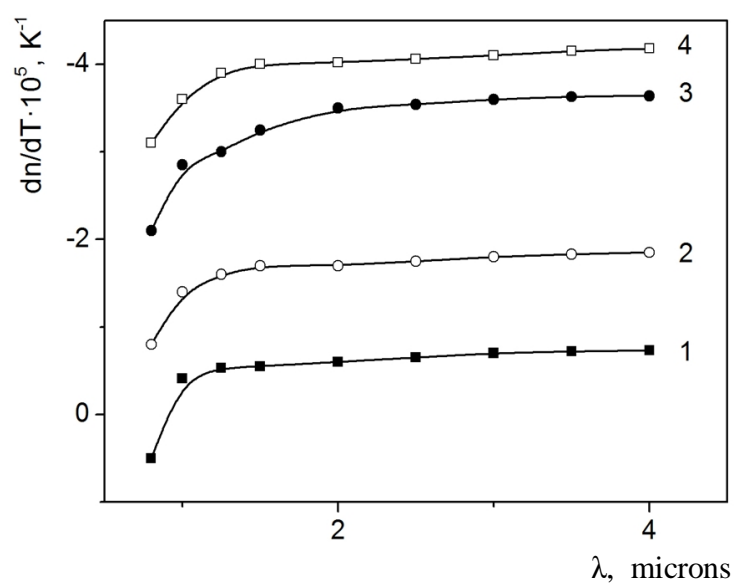

Fig. 1. Spectral dependence of $\mathrm{dn} / \mathrm{T}$ glass fiber alloys of the section (Ag2S) x $($ As2S3) 100-x: 1 As40S60; $2-\mathrm{x}=5 ; 3$ to $10 ; 4-15$.

dependences of the eigenfrequencies and the dispersion parameters of the equivalent oscillators, or for this purpose relations are used that correlate the refractive index and the band gap width (for example, the Moss rule [11], the Wempla-Di Domenico-Ravindra ratio [10], the optic-refractometric regularity [16], etc.). The temperature dependence of $n$ was determined by the displacement of the edge of the own absorption with the temperature, and by the influence of the abovementioned own resonances neglected. This approach [17] allowed a generally satisfactory qualitative description of the behavior of the temperature dependences $n(T)$ in both crystalline and amorphous semiconductors, including the identification of the sign $d n / d T$, and to evaluate the magnitude of TKPZ with accuracy within the order of magnitude.

Figure 1 shows the spectral dependence of $d n / d T$ glass-fiber alloys of the $\mathrm{Ag}_{2} \mathrm{~S}-\mathrm{As}_{2} \mathrm{~S}_{3}$ system, from which it follows that $d n / d T$ is weakly dependent on the wavelength $\lambda$, and a noticeable spectral dependence begins to appear in the region $\lambda<1.5$ microns. For the glass $\mathrm{As}_{2} \mathrm{~S}_{3}$, the parameter $d n / d T$ changes the sign in the variation of the wavelength in the region of $\lambda \sim 1 \mu \mathrm{m}$, and for other syllables its negative value is characteristic. In addition, for all investigated compositions, there is a significant dependence of the temperature coefficient of refractive index (TKPZ) on temperature: $d n / d T$ increases with increasing $T$.

According to [17], using a uniaxial model, the coefficient $\beta=d n / d T$ for solids in the region far from the phonon absorption bands $(\lambda>10 \div 12 \mu \mathrm{m})$ can be represented as a sum of two components:

$$
\frac{d n}{d T}=-\frac{6 \pi \chi_{e}}{n} \alpha-\frac{4 \pi \chi_{e}}{n} \frac{1}{\omega_{g}} \frac{d \omega_{g}}{d T} \frac{1}{1-\left(\frac{\omega}{\omega_{g}}\right)^{2}},
$$

where $\alpha$ is the coefficient of linear expansion, $\chi_{e}$ is the electron polarization (susceptibility), $\omega_{g}$ is the frequency of the oscillator. The first component occurs due to the change in the density of matter, the second - due to the temperature change of its electronic structure, that is, the change in the magnitude $\omega_{g}$.

Given that the parameter $d \omega_{g} / d T$ is generally negative, the components (6) respectively have opposite signs. In the visible spectral region for the CHF system, the predominant contribution to $d n / d T$ is made by the first component. As the proximal self absorption band $(\omega$ $\left.\rightarrow \omega_{g}\right)$ approaches, the contribution of the second component increases, and for certain (characteristic) wavelengths $\lambda_{0}$, these components are mutually balanced

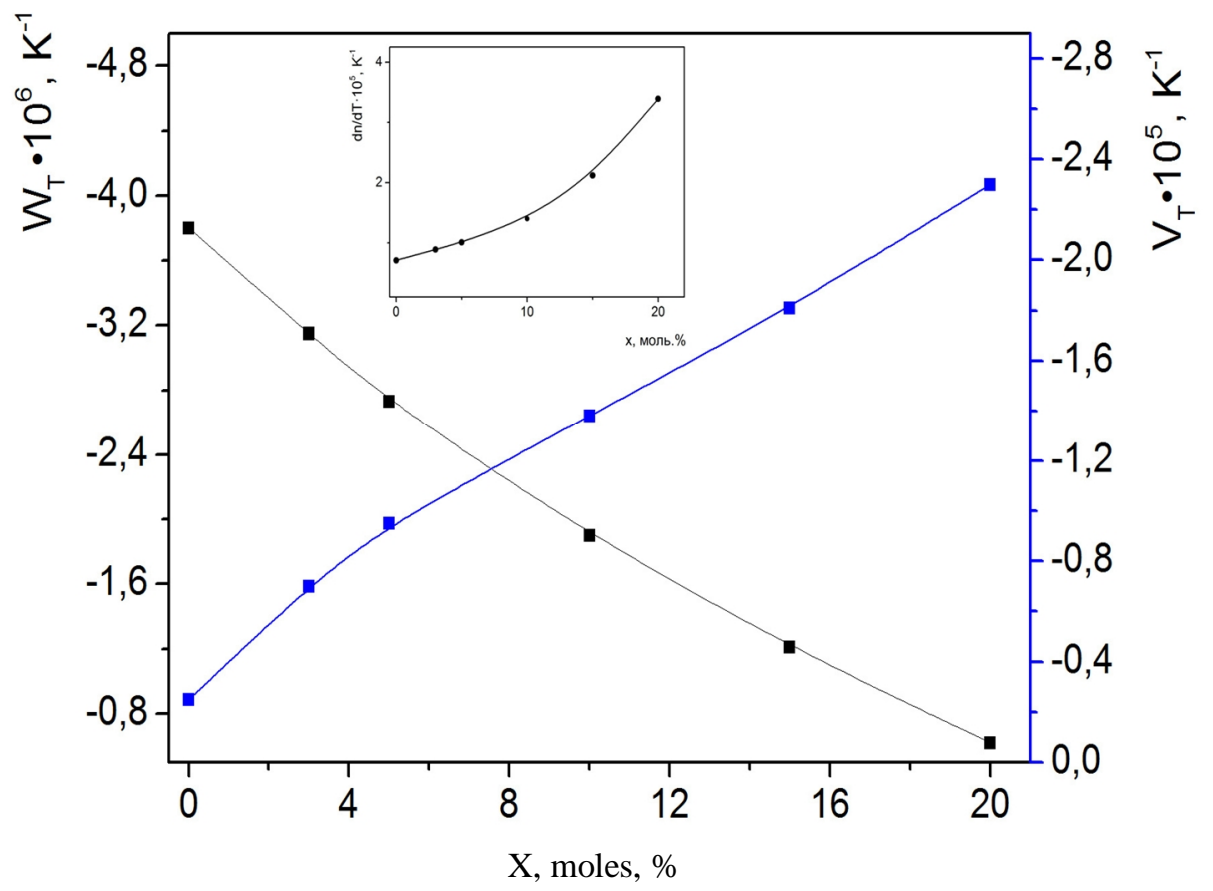

Fig. 2. Concentration dependence of thermoelectric aberrations $W$ and VT. On the insert - the dependence of TKPZ on the composition of alloys. 
$(d n / d T=0)$, and for the wavelengths smaller than some limiting $\lambda_{0}$ the second The component determines the sign of the temperature derivative $n$. In addition, the obtained results indicate that the value of $\lambda_{0}$ depends on the size of the band gap of the glasses under study, or in other words, the smaller $\omega_{g}$, the greater $\lambda_{0}$. For the studied glasses, the determined values of $\lambda_{0}$ are in the range of 1-3 microns. Among the studied alloys of the Ag-As-S system, only the stoichiometric composition of $\mathrm{As}_{2} \mathrm{~S}_{3}$ takes the value $d n / d T=0$ with a defined value of $\lambda_{0}$ equal to $\sim 0.96 \mu \mathrm{m}$. For other compositions, the values $\lambda_{0} \rightarrow d n / d T=0$ are outside the studied region of the spectrum. The negative value of the coefficient $d n / d T$ indicates the fact that in the investigated part of the spectrum, the temperature change of the density of glasses plays a dominant role. In fig. the concentration dependences of the parameter $d n / d T$ and the thermoelectric aberration are given.

So this model with qualitative side explains well the experimental results, in quantitative terms, according to [17], this model gives good results for $\lambda>1.5$ microns (ie away from the absorption bands). If, based on the expression (5) using the values $d \omega_{g} / d T$, given in [18] found value $\lambda_{0}$, it will almost $\sim 1.5$ times less experimental, that near field absorption, this model is not suitable for quantitative assessments. The fact that the energy state of heart failure should be described with a few oscillators with different forces and then accordingly if in an area remote from the absorption bands, oscillators can be replaced effectively, in less remote areas should consider all oscillators separately.

To analyze the dependence of $d n / d T$ on $T$, we differentiate the formula (5). If we ignore relatively small (for a region $\lambda>3 \mu \mathrm{m}$ ) second term, then we obtain that

$$
\frac{d}{d T} \frac{d n}{d T}=\frac{d}{d T} \frac{6 \pi \chi_{e}}{n} \alpha .
$$

Thus, the dependence of $d n / d T$ on $T$ is determined by the dependence of $\alpha$ on $T$ (taking into account the dependence of $n$ and $\chi_{e}$ on the temperature introduces in this case insignificantly small corrections). In addition, from (6) it follows that the behavior of the temperature dependence of the coefficient $d n / d T$ and the magnitude $\left(6 \pi \chi_{e} / n\right)$ is symbat able, that is, they must be mutually parallel. In fig. 3 as an example, the dependencies indicated for $\mathrm{As}_{2} \mathrm{~S}_{3}$ are given at $\lambda=3 \mu \mathrm{m}$.

Expression (5) is not suitable for describing the dependence of $d n / d T$ on $T$ for $\lambda<1 \mu \mathrm{m}$ and especially at the point $\lambda_{0}$, where $d^{2} n / d T^{2} \sim 0$. In this case, even taking into account other members obtained in the differentiation (6), the value of $d n / d T \sim 0$ can be obtained only for $\omega$, very close to $\omega_{g}$. This means that a singleoscillatory model can not be applied to quantitative estimates in the spectral region close to the selfabsorption bands. Proceeding from the obtained results

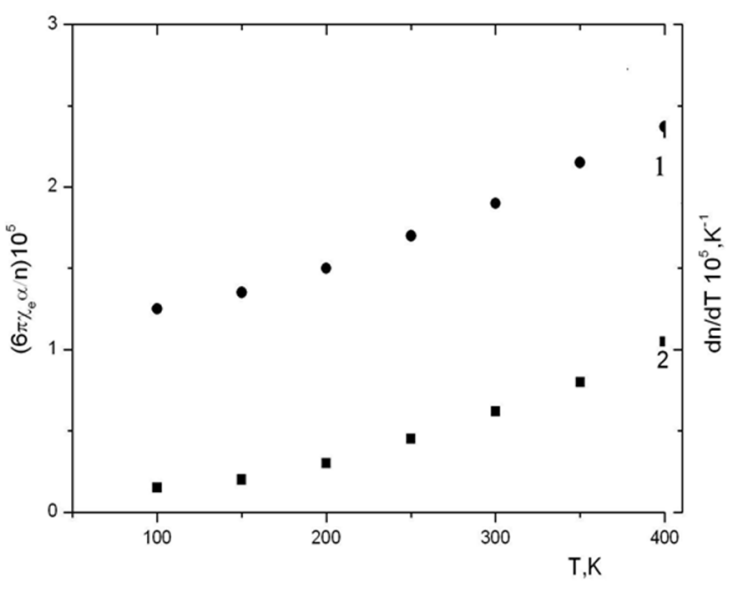

Fig. 3. Temperature dependence of the value $(6 \pi \chi \mathrm{e} /$ n) $\alpha$ (1) and the coefficient dn/dT (2) for the As40S60 glass.

of the study of the temperature-spectral dependences of the refractive index of the glass system, a uniaxial model from a qualitative side gives a good explanation of the results. Nevertheless, in spite of a number of simplifications made in the calculations, the relation (6) on the basis of this model satisfactorily describes the dependence of $d n / d T$ on $\lambda$ and $T$ in the field of transparency for glasses of the Ag-As-S system can be used to analyze the dependences $n(T)$, and for other multicomponent glassy chalcogenide semiconductors.

\section{Conclusion}

It is shown that the temperature-spectral dependence of the refractive index of glass-fiber alloys of the Ag-As$\mathrm{S}$ system can be satisfactorily explained within the framework of a single-oscillatory model. The magnitude and sign of the temperature coefficient of the refractive index is determined by two contributions: due to changes in the temperature of the density of glasses and the temperature change of the energy structure of glass. It is established that the given model is not suitable for quantitative estimations in the spectral range close to the self absorption bands.

Shpak O. - Lecture of the Departament of Software Systems of the Faculty of information Technologies, Researcher;

Studenyak I. - Dr.Sc (physical and mathematical science), professor;

Shpak I. - PhD, assistant professor of semiconductors physics department, Senior Research. 
[1]. A. Andriesh, Physics and Applications of Non-Crystalline Semiconductors in Optoelectronics (Kluwer Academic Publiechers, Dordrecht, London, 1997).

[2]. X. Zhang, J.of Optoelec. and Advanc. Mat., 5(5) (2003) 1327.

[3]. J. Teteris, M. Reinfelde, J. of Optoelektronics and Advenced Materials, 5(5) (2003) 1355.

[4]. J. Pedlikova, J. Zavadil, O. Prochazkova, D. Lezal, J. of Optoelektronics and Advenced Materials, 9(6) (2003) 1679.

[5]. S. Miyatani, J. of Phys. Soc. J., 50(10) (1981) 3415.

[6]. A. V. Mezenov, L. N. Soms, A. I. Stepanov, Thermooptucs of solid state lasers (Mashynostroenie, Leningrad, 1986).

[7]. O. S. Shchavelev, Optico-mechanical promyshlennostj, 7, (1974) 73.

[8]. O. S. Shchavelev, Physics and Chemistry of Glass, 2(5), (1975) 449.

[9]. P. P. Puga. Temperature spectral - structural changes and optical properties of AV - BVI - CII chalcogenide glasses: Dr. Sci. Thesis, Institute of Physics NAS of Ukraine, 36 p. (1989).

[10]. S. S. Batsanov, Structural refractometry (High School, Moscow, 1976).

[11]. T. Moss, Optical properties of semiconductors (Inostr. Literat., Moscow, 1961).

[12]. A. I. Erohin et al. J. Exp. Theor. Phys., 74(4), (1978) 755.

[13]. R. M. Waxler, G.M. Gleek, J. Res. Mat. Bur. Stand. A., 77(6), (1973) 755.

[14]. T. Narasimkhamurti, Photoelastic and electro-optical properties of crystals. (World, Moscow, 1984).

[15]. G. N. Ramachandran, Proc. Indian Acad. Sci., A25, (1947) 481.

[16]. A. N. Borets, Ukr. Phys. Journ., 28(9), (1983) 1346.

[17]. Y. F. Tsay, D. Bendov, S. S. Mitra, Phys. Rev. B, 8(6), (1973) 2688.

[18]. A. N. Borets et al. Complex glassy chalcogenides (preparation, properties, application) (Vishcha school, Lviv, 1987).

\author{
O.I. Шпак, I.П. Студеняк, I.I. Шпак
}

\title{
Температурна залежність показника заломлення скловидних сплавів системи $A g-A s-S$
}

\footnotetext{
Ужсгородський нациіональній університет, Украӥна, м. Ужсгрод, вул. Підгірна, 46; e-таil: shpak.univ@ gmail.com

В спектральному інтервалі 1-5 мкм при температурах $77-400$ К досліджено концентраційну поведінку температурного коефіцієнта показника заломлення $d n / d T$ (ТКПЗ) скловидних сплавів системи $\mathrm{Ag}-\mathrm{As}-\mathrm{S}$ по розрізу $\left(\mathrm{Ag}_{2} \mathrm{~S}\right)_{\mathrm{x}} \cdot\left(\mathrm{As}_{2} \mathrm{~S}_{3}\right)_{100-\mathrm{x}}, \mathrm{x}=0-20$ моль. \%. В рамках одноосциляторної моделі проведений аналіз спектральної і температурної залежності даного коефіцієнта.

Ключові слова: халькогенідні стекла, температурний коефіцієнт показника заломлення, одноосциляторна модель, смуга поглинання.
} 